\title{
Should we expect bilingualism to confer cognitive benefits in children with autism spectrum disorders?
}

\begin{abstract}
This article examines the ways in which bilingualism influences social and cognitive development and identifies intersections between corresponding aspects of autism, to inform future research directions. Three key domains are identified: social cognition; executive functions; and social-cultural factors. In each case we describe the evidence for the impact of bilingualism in typical development and map this onto what is known about the domain in autism. We examine the methodological quality of the existing literature to make recommendations for future approaches. Results suggest a dearth of high-quality research and lack of consensus. Research priorities include the need for innovative designs to explore potential impacts of bilingualism in order to increase the validity of the evidence base for caregivers and professionals.
\end{abstract}

Key Words: Autism spectrum disorders, bilingualism, executive functions, language, social cognition, cultural identity. 


\section{Should we expect bilingualism to confer cognitive benefits in children with autism spectrum disorders?}

Autism Spectrum Disorder (hereafter autism) is a neurodevelopmental condition characterised by lifelong difficulties in social and communicative domains, restricted, repetitive behaviours and interests and sensory and perceptual features (American Psychiatric Association (APA), 2013). Autism is associated with intellectual disability in around 55\% of cases (Charman et al., 2011) and language delay is the most common cause of initial referral to specialist services in children (Dover, 2007).

Language proficiency and use are highly heterogeneous between autistic individuals. Whilst some develop language skills within a typical range and timeframe, others experience significant difficulties (Kjelgaard \& Tager-Flusberg, 2001). Individuals with lower verbal fluency may exhibit difficulties across multiple aspects of language skills including vocabulary (Mitchell, 2006), syntax (e.g. difficulty with relative clause comprehension; Durrleman, Hippolyte, Zufferey, Iglesias \& Hadjikhani, 2015), morphology (such as the omission of past tense morphological markers; Tager-Flusberg, 2004) and phonology (such as difficulties with the repetition of nonsense words; Kjelgaard \& Tager-Flusberg, 2001). In some cases, language problems may be attributable to co-occurring developmental language disorder (Bishop \& Norbury, 2002; Norbury \& Bishop, 2002). Nonetheless, difficulties with pragmatic language are a core feature of autism and are often present even in those who are not impaired in other aspects of language (Paul, Landa \& Simmons, 2014; Tager-Flusberg et al., 2009). This includes comprehension of non-literal language such as metaphor, irony and faux pas (BaronCohen, O'Riordan, Stone, Jones, \& Plaisted, 1999; Happé, 1993). Other challenges include conversation-based skills, such as turn taking during conversation, structuring narratives, taking another's perspective during conversation and the ability to repair communicative breakdown (Geller, 1998; Paul, Landa \& Simmons, 2014; Surian, Baron-Cohen, \& van der Lely, 1996).

Bilingualism is a widespread phenomenon, with estimates suggesting that more than half of the world's population may be bilingual, and increasing numbers of bilingual families worldwide (Grosjean, 2010). Bilingualism can be defined as proficiency in two or more languages, but the manifestation of this is highly heterogeneous, such that the term "bilingualism" covers a spectrum of proficiently levels, ages of acquisition, and language use in daily life (Marian, 2018). The communicative difficulties common to many autistic people raise important practical and theoretical questions about how language may develop for autistic people in 
multilingual environments. In particular, many parents of bilingual, autistic children worry that delays in language acquisition, or pragmatic challenges of language use may be exacerbated if their child is raised in a bilingual environment, (Kay-Raining Bird, Lamond, \& Holden, 2012;) or that exposure to bilingualism will be confusing (Yu, 2013). Research suggests that practitioners can share this view and frequently advise parents in English-speaking countries to consider a majority-language, monolingual environment for their child (Hampton, Rabagliati, Sorace \& Fletcher-Watson, 2017).

However, concerns about language development have so far not been supported by the literature focusing on typically developing children, or in children with developmental conditions. In typically developing bilingual children, early language milestones such as babbling and first words are acquired at a rate within the typical range (Holowka, Brosseau-Lapré, \& Petitto, 2002). The vocabularies of bilinguals are equivalent to those of monolinguals when they complete assessments in both languages (Hoff et al., 2012; Petitto et al., 2001), though bilingual children may demonstrate poorer vocabulary and syntax than their monolingual peers when only one of their languages is assessed (Gathercole \& Thomas, 2009). Furthermore, findings consistently demonstrate that if children experience delays in language acquisition, they catch up by late primary school age (Paradis,Genesee, \& Crago, 2011).

A smaller body of work has directly examined effects of bilingualism outside of typical development, suggesting that exposure to more than one language does not delay acquisition of vocabulary and grammar in children with developmental conditions such as specific language impairment (Korkman et al., 2012) and Down syndrome (Feltmate \& Kay-Raining Bird, 2008). Likewise, no significant differences have been identified between monolingual and bilingual autistic children on parent report measures of receptive and expressive vocabulary (Hambly \& Fombonne, 2012), age of early language milestones (Ohashi et al., 2012), or structural language or pragmatics (Reetzke, Zou, Sheng, \& Katsos, 2015; Meir \& Novogrodsky, 2019). Recent systematic reviews reinforce this conclusion (e.g. Marinova-Todd \& Mirenda, 2015; Uljarevic et al., 2016; Beauchamp \& Macleod, 2017).

However, the impact of early language environment extends well beyond language itself. Additional domains of impact include facilitating family and community relationships, access to services, cultural identity factors, and possible cognitive influences. All of these have key importance for autistic children growing up. In this review, we systematically explore the domains purported to be impacted by bilingualism, and how these 
connect to autism, in order to provide a conceptual framework for future research investigations of bilingualism in autism.

\section{Methods}

This review of the literature set out to chart the evidence on domains of development affected by bilingualism, and demonstrate connections between this and known areas of relevance to autism. We examine evidence on bilingual effects in typical development, related domains in autistic monolingual development, and the small amount of literature directly addressing autism and bilingualism beyond the language domain.

Relevant literature was identified through online searches for keywords such as 'autism', 'bilingualism', 'cultural issues', 'language development', 'neurodevelopmental disorders' and their variations. Online searches were conducted using websites such as "Google Scholar", "PsycINFO", "PubMed" and "ScienceDirect". Further literature was also sourced through hand searches conducted of the reference sections of relevant articles. Identified literature relevant to the topic of autism and bilingualism was then read and drawn together in order to identify gaps in the current state of knowledge and to propose areas where autism and bilingualism could overlap.

The resulting papers were organised by topic, and the review evaluates the relevant literature in these categories, which are: social cognition, executive functions and literature surrounding socio-cultural factors and emotional wellbeing. We examined the general methodological limitations in the autism and bilingualism literature that have, thus far, made generalisability difficult; we focused on the heterogeneity of bilingualism terminology, problems with current approaches to measuring the impact of bilingualism, and variability in autism.

\section{Social cognition}

There is the possibility that putative benefits conferred by bilingualism might serve to mitigate some of the social difficulties experienced by autistic people (although it is also possible that difficulties with social cognition in autism impede effective bilingualism, which we discuss below). There are several areas relating to social cognition where benefits from bilingualism and difficulties associated with autism converge: communicative gesture, pragmatic language and theory of mind (ToM). 


\section{Communicative Gesture}

Gestures can be described as symbolic movements that are highly relevant for communication with others, and frequently co-occur with speech. (Gullberg, 2010). Gesture plays a fundamental role in language and social development (Manwaring, Mead, Swineford \& Thurm, 2017) and can be viewed as a significant communicative resource, influenced by social context and cultural environments (Gullberg, 2010). Gesture is highly interconnected with language production and comprehension (Goldin-Meadow, 2003). It is a robust predictor of later developing language skills (Iverson \& Goldin-Meadow, 2005) and is theorised to be a crucial precursor for developing high-quality social relationships (Bishop, 2014).

Bilingualism is associated with more frequent gesture use compared to monolinguals (Nicoladis, Pika, \& Marentette, 2009) In additional, neurotypical bilinguals exhibit advantages in using gesture to understand referential intent (such as pointing) and other communicative cues (such as gaze direction) to understand referential intent from at young as two years old (Yow \& Markman, 2011). The authors argue that children growing up in a bilingual environment may need to increasingly update and monitor the communicative context of social interactions in order to express their intentions appropriately; this additional effort could allow children to utilise referential gestures, and therefore referential intent.

Conversely, autism is commonly associated with challenges relating to non-verbal communication. There is evidence of reduced use of gestures (such as pointing and showing) in autistic children (Watson, Crais, Baranek, Dykstra, \& Wilson, 2013), and correlations between infrequent gesture use and higher levels of autistic behaviours as measured by the ADOS (Manwaring, Mead, Swineford \& Thurm, 2017).

Is it possible however, that bilingualism could facilitate increased frequency and improved use of gesture amongst autistic children. Indeed, preliminary evidence shows that bilingually exposed autistic children may demonstrate increased use of gesture. Valicenti-McDermott et al. (2013) found that bilingually exposed autistic children used more communicative gestures such as pointing and leading to desired objects (although it should be noted that a description of 'leading to desired objects' is not given, leaving the possibility open that this refers to hand-leading, a characteristic of autism (Paul, 2007). The same children also engaged in more imaginative play, such as pouring from an empty container, compared to their monolingual counterparts.

Given that early gesture and play behaviours both precede and are fundamentally linked to language learning (Hall, Rumney, Holler, \& Kidd, 2013) and vocabulary growth (Rowe, Ozcaliskan \& Goldin-Meadow, 
2008), the additional acquisition of these skills may be highly beneficial for autistic children, particularly in early childhood, where additional gesture use could provide an opportunity to provide a scaffolding role for building social relationships.

\section{Pragmatic Language}

Pragmatic language is a term used to describe elements of language comprehension predominantly used in social contexts; in particular, the ability to use language in specific situations to enrich communication (Prutting \& Kirchner, 1987). Pragmatic skills including turn taking in conversation, listening and speaking using and understanding body language, and understanding language context. These skills are associated with emerging emotional processing and social abilities (Parsons, Cordier, Munro, Jooste \& Speyer, 2017) and difficulties with pragmatic aspects of language can lead to persisting difficulties creating and maintaining social relationships (Whitehouse, Watt, Line \& Bishop, 2009).

Bilingualism is associated with advantages in aspects of pragmatic language (Siegal et al., 2010). For example, neurotypical bilingual children have been found to demonstrate superior performance at detecting violations of conversational maxims (Siegal, Iozzi, \& Surian, 2009). Children speaking both Italian and Slovenian exhibited higher accuracy levels when asked to identify whether a speaker has failed to be informative, truthful, relevant and polite compared to monolingual controls.

On the other hand, autistic people frequently present difficulties in this domain. As previously mentioned, such challenges are likely to persist throughout the lifespan and are often exacerbated in adulthood; for example, many autistic people have increased difficulty producing novel language and make fewer attempts at initiating communication (Parsons, Cordier, Munro, Jooste \& Speyer, 2017).

If bilingualism could positively impact the development of pragmatic language skills for neurotypical bilinguals, it could also offer an opportunity to target an area of long-term and pervasive difficulty for autistic individuals. To date, one study has focused on pragmatic skills in autistic bilingual individuals. No differences were identified in pragmatic language skills between 23 bilinguals and 31 monolinguals in a parental report (Reetzke et al. 2015). Future research would benefit from the Inclusion of direct assessments to measure specific aspects of pragmatic language. While results suggest a lack of negative association between bilingual exposure and pragmatic language development, there remains the possibility that bilingualism could facilitate understanding of conversational maxims amongst autistic people. 


\section{Theory of Mind}

Theory of mind (ToM) is defined as the capacity to reflect on one's own and others' mental states (Baron-Cohen, Leslie \& Frith, 1985). It is an important aspect of social cognition and is associated with effective communication strategies, such as sharing knowledge in ways that allow people to understand one another's intentions (Sidera, Perpina, Seranno \& Rostan, 2018).

Considering the interplay between bilingualism and ToM abilities, researchers have proposed mechanisms by which bilingualism could facilitate advantages. One theory relates to the practice of tailoring language to the linguistic knowledge of one's interlocutor. Bilingual children will switch languages to attract their mother's attention (Rontu, 2007), and bilingual pre-school aged children have been shown to switch languages to match that of an experimenter to repair communication breakdown (Comeau, Genesee, \& Mendelson, 2007). Alternatively, bilinguals' practice in controlling multiple languages could lead to enhancement of their executive control abilities that are required for successful performances across ToM tasks. Bilingual children and adults frequently outperform monolinguals on ToM tasks (including appearance-reality, perspective-taking and false-belief tasks (Goetz, 2003; Kovács, 2012; Rubio-Fernández \& Glucksberg, 2012)).

In contrast, difficulties with ToM skills for autistic people are widely reported in the literature (BaronCohen, 2001; Senju, 2012). There is evidence that autistic people face challenges in aspects of ToM such as false belief tasks (Baron-Cohen, Leslie, \& Frith, 1985) and faux-pas recognition (Baron-Cohen et al., 1999; Beaumont \& Sofronoff, 2008). However, abilities are heterogeneous across individuals, (Scheeren, Rosnay, Koot, \& Begeer, 2013), and contradictory findings may be attributable to different methodologies (Bloom \& German, 2000).

To the extent that ToM difficulties are apparent across autistic people, bilingualism could help to mitigate some of these difficulties. One potential mechanism for a bilingual advantage in social cognition is that bilingualism provides training in adapting language use to the social context. It is also possible, however, that a neurotypical bilingual advantage in social cognition does not hold for autistic children. The ability to utilise language in a way that accounts for the linguistic knowledge of others would presumably require a certain level of ToM abilities. Rather than bilingualism helping to reduce social cognition difficulties by providing a naturalistic training opportunity, it may be that a bilingual environment could be additionally challenging for autistic children who need to adapt their language to use the social context. 
Research focusing on neurotypical bilingual development points to promising avenues for future research into the potential benefits of bilingualism on social cognition. Based on the association between potential benefits of bilingualism and areas of difficulty associated with autism, future research should attempt to establish whether bilingualism is associated with social cognition difficulties, or rather these difficulties decrease effective use of multiple languages for autistic children. For example, if social cognition abilities facilitate bilingualism, it might be expected that autism could make it more difficult for children to become effective bilinguals. On the other hand, if bilingualism influences social cognition, then we would expect to see evidence of effective bilingualism.

It may be the case that a certain level of social abilities is required in order to begin to tailor one's language use to the social context, and that these skills are then honed through the repeated practice that a bilingual environment provides. It may then be the case that bilingualism would advantageous for some groups of children. Furthermore, if autistic children do find adapting their language use especially challenging, this may give rise to a greater risk of communicative breakdowns (for example, if a child attempts to communicate in a language their interlocutor does not know). Currently, only one case study has focused on language adaptation to use context; in this case, an autistic child was found to engage in code-switching in a strategic and systematic manner (Yu, 2016). However, sufficiently powered and diverse studies will provide greater insight into the mechanisms underpinning bilingual effects on cognition in autistic and neurotypical children.

\section{Executive functions}

Executive function (EF) is an umbrella term for a set of processes that underlie goal-oriented behaviours including planning, inhibition, cognitive flexibility, and working memory (Anderson, 2002). Based on the extent to which we rely on EF skills for everyday functioning, it is unsurprising that the impact of bilingualism on executive functions is a topic of considerable interest. Thus far, however, findings are varied. As we discuss below, several studies have reported advantages for bilingual children across of range of EF tasks (Bialystok, 2009), while others report a lack of group differences between monolinguals and bilinguals within the same subdomains (Paap \& Greenberg 2013; Kroll \& Bialystok 2013).

Autism is commonly associated with EF difficulties (e.g. Hill, 2004), with children generally exhibiting lower performance levels across EF tasks (Kleinhans, Akschoomoff \& Delis, 2005). It is therefore an exciting (yet tentative) possibility that possible bilingual advantages across EFs could serve to mitigate some EF 
impairments seen in autism. Although claims of such advantages in both autism and neurotypical development remain controversial, we review the central components of EF in turn, focusing on those for which there is an association to both bilingualism and autism.

\section{Inhibition and task-switching}

Inhibition is a collection of processes that allows the allocation of attention away from irrelevant information and the suppression of inappropriate actions and behaviours. Inhibition enables individuals to provide appropriate responses and filter distracting incoming stimuli, and can apply to both social and nonsocial situations (Adams \& Jarrold, 2011).

The literature surrounding the effects of bilingualism and inhibition for neurotypical bilinguals is inconclusive. One theory for a bilingual advantage in inhibition skills is that bilinguals are able to practise suppressing intrusions from one language while using the other (Kroll, Bobb, Misra, \& Guo, 2008). Inhibition is frequently measures using the Simon task; two different coloured stimuli can appear on the left or right side of the screen. Participants must press a key on the right side of the keyboard when they see one of the stimuli, and a key on the left when they see the other. When the stimulus appears on the same side as its response key, the trial is congruent and when it appears on the opposite side, the trial is incongruent. Bilinguals tend to show a smaller congruency effect - that is, they show less of an increase in time required for trials featuring incongruent as opposed to congruent information (Bialystok, Craik, Klein, \& Viswanathan, 2004; Martin-Rhee \& Bialystok, 2008). This finding is presented by some as clear evidence for a bilingual advantage in tasks involving inhibition. However, findings have been contested, with many studies reporting no differences between monolinguals and bilinguals (Duñabeitia et al., 2014; Humphrey \& Valian, 2012; Paap \& Greenberg, 2013). Any bilingual advantage in inhibition may be most apparent for older speakers and least apparent for young adults (Valian, 2015). Advantages may also be less apparent when studies carefully control for confounding factors such as socio-economic status (Morton \& Harper, 2007) and language ability (Gathercole et al., 2016).

Traditionally, impairments in inhibition have been reported in autism after controlling for age and IQ (e.g. Christ, Holt, White, \& Green, 2007). However, findings in the autism literature are not uncontroversial; other studies have shown that autistic and neurotypical children perform at comparable levels (Russell, Jarrold \& Hood, 1999). Inconsistencies between findings may be explained, at least in part, by the tasks used. For example, studies report lower performance levels from autistic people on tasks requiring the inhibition of irrelevant distractors (although inhibition of a prepotent response (as measured, for example, by the Stroop task) 
has often been found to be unimpaired compared with age-matched controls (Adams \& Jarrold, 2012; Goldberg et al., 2005)). However, others have also demonstrated comparable group findings in autistic people when participants were asked to inhibit irrelevant information (e.g. Ozonoff \& Strayer, 1997); although such studies have been criticised on methodological grounds (Adams \& Jarrold, 2012).

Task switching is a related executive process, potentially enhanced by bilingualism. Task switching is defined as the ability to switch between one task and another when required (Emerson \& Miyake, 2003). One proposed mechanistic explanation for such advantages is that switching flexibly between languages may improve the ability to switch flexibly between other, non-linguistic tasks (Prior \& Gollan, 2011). Bilingual task switching advantages have been reported in neurotypical children (Bialystok \& Martin, 2004) and adults (Prior \& MacWhinney, 2010). However, other studies have found no bilingual advantage in task-switching per se, using similar tasks. It is possible that an advantage is apparent for those who switch frequently between languages, though one study found no bilingual task switching advantage amongst bilinguals who language switch frequently, when matching closely on demographic variables such as socio-economic background (Paap and Greenberg, 2013). However, caution is warranted when interpreting the results of this particular study, given that it offered no clear measure of bilingualism and included bilinguals from heterogeneous bilingual circumstances.

Though task-switching is not part of the diagnostic criteria for autism, difficulties with related behaviours are frequently reported (this include difficulty with task transitions and a preference for sameness (Leekam,, Prior \& Uljarevic, 2011). Some research shows that autistic individuals are frequently outperformed by neurotypical controls on measures such as the Wisconsin Card Sorting Task (WCST), which requires participants to sort cards according to one rule and then switch to another. A common finding is that children, adolescents and autistic adults tend to perseverate on the WCST and similar tasks in comparison to age and IQ matched controls, experiencing difficulty shifting to a new rule (Lopez et al., 2005; Ozonoff \& McEvoy, 1994; Van Eylen et al., 2011). Once again, however, there is evidence of typical-range ability in task-switching using similar tasks (Geurts, Corbett, \& Solomon, 2009). Inconsistent findings in this area may be in part due to methodological issues. For example, studies in this area employ wide age ranges (Van Eylen et al., 2011) and impairments can be more apparent when autistic and control groups are not matched on verbal ability (Burack et al., 2002). 
Thus far, one study has investigated the relationship between bilingualism and task-switching abilities in autistic children (Gonzalez-Barrero \& Nadig, 2019). In a sample of 10 bilingual and 10 monolingual autistic children, a significantly higher percentage of bilingual children were able to complete a computerised dimensional card sorting task, requiring higher levels of task switching. This provides preliminary evidence for good or potentially enhanced performance for bilingual autistic children, relative to monolinguals, in tasks requiring attentional switching. However, no group differences were found in parent report measures of setshifting skills in daily life. The authors suggest that inconsistencies between enhanced abilities in a lab environment, and lack of differences between groups from parent reports could be due, in part, to differences in social and cognitive load for different tasks; computerised tasks could provide a more comfortable learning environment for some children, with reduced social demands and unambiguous rules. If enhanced switching performance using computerised tasks was replicated with a larger sample, the authors suggest the possibility of incorporating switching tasks where children perform well into future interventions, to begin building on cognitive flexibility skills in daily life.

Findings relating to bilingualism, inhibition and task-switching, then, are equivocal. If advantages do exist, it is possible that, rather than benefits in inhibition or task-switching per se, the bilingual advantage lies in more general executive processes. For instance, a bilingual advantage has been found on congruent as well as incongruent trials of the Simon task and any bilingual advantages seen may be driven by overall reaction time differences (Costa, Hernández, \& Sebastián-Gallés, 2008; Morton \& Harper, 2007). Alternatively, a bilingual advantage may only be apparent under more taxing conditions, as found by Martin-Rhee and Bialystok (2008) in a version of the Simon task where incongruent trials formed $50 \%$ of total trials rather than $25 \%$. It has been suggested that the general executive advantage conferred by bilingualism may lie in maintenance of goal representations throughout a task (i.e. monitoring or proactive control), an advantage that may arise from bilinguals' experience with monitoring context in order to select which language to use (Colzato et al., 2008; Costa, Hernández, Costa-Faidella, \& Sebastián-Gallés, 2009). Indeed, studies have found a bilingual advantage on measures which make high demands on such processes, such as multi-tasking measures (Craik \& Bialystok, 2006).

Similarly, in response to equivocal evidence for EF impairments in autism, it has been suggested that EF difficulties in autism do not pertain to sub-processes such as inhibition and task-switching, but rather only become apparent in the most open-ended and ill-structured of tasks. An example of such tasks might be those 
requiring the flexible control of attention between stimulus dependent and independent thought (Hill \& Bird, 2006). Supporting this, even those autistic people who pass traditional EF tasks may still have difficulties with more challenging tasks such as measures of multi-tasking, which require participants to keep in mind a complex internal plan while dealing with the demands of the environment (White, Burgess, \& Hill, 2009). There remains the possibility, then, despite controversies within the separate literatures, that bilingualism could provide useful training in tasks which require controlling attention between task rules and task stimuli. One area for future enquiry may be whether bilingualism can provide advantages for autistic individuals on more ecologically valid, demanding executive tasks such as multi-tasking.

It also remains a possibility that, rather than bilingualism reducing EF difficulties for autistic people, the EF difficulties in autism create an additional obstacle in achieving proficient levels of bilingualism (as discussed in relation to social cognition in the preceding section). In this sense, evaluating the direction of interactions between bilingualism and executive function skills in autistic children could provide robust evidence for some of the claims of bilingual advantages in the general literature. For example, If bilingualism relies on EF supported skills, such as the ability to inhibit one language while using another, to switch flexibly between languages or to multi-task, it may be that autistic people find the demands placed on these skills too challenging, rather than receiving an opportunity to hone their skills. Therefore, if it is the case children must possess robust executive function skills, autistic children should demonstrate greater difficulties in acquiring dual language proficiency in general.

However, there is suggestive evidence of a bilingual advantage in EF in two studies, at least for autistic children with IQ's within a typical range. Gonzales-Barrero \& Nadig (2019) demonstrated task-switching advantages under particular conditions (see inhibition and task switching), and a second small study finding more accurate responses on a working memory task, as well as a greater tendency to process stimuli globally rather than locally, among bilingual compared with monolingual autistic children (Baldimtsi, Peristeri, Tsimpli \& Nicolopoulou, 2016).

Social-cultural factors and emotional well-being

Perhaps the most overlooked area of development in which autism and bilingualism interact is socialcultural factors, emotional well-being, and family quality of life. While bilingual exposure may not be driving 
cognitive or mechanistic changes underlying social-cultural and emotional wellbeing, it can help children to adapt to their environment in ways that otherwise they may not be able to.

Family cohesion has been defined as the bonds that hold a family together (Verkuyten and Zaremba 2005) and is considered to be a central component of family wellbeing. There are multiple factors relating to family cohesion that play a major role in multilingual families, including quality of family communication and time and allocation of heritage learning (Wang \& Casillas, 2013).

Studies have shown that children from minority language-speaking families benefit from the close familial and cultural connections that speaking the minority language affords, and that these benefits may further be associated with social and emotional wellbeing (Halle et al., 2014; Han \& Huang, 2010). Some research shows that bilinguals change or express different social-cultural expectations with a change in linguistic code, or language use (Panayiotou, 2004). Furthermore, the ability to correctly express and label emotions have also been linked to mental health (Goleman, 1996). Parents may feel more able to connect emotionally with their child in their home language, given the association between one's native language and emotional processing (Opitz \& Degner, 2012). For example, research shows that sequential bilinguals can experience their second language as less emotional with high levels of dual-language proficiency. Although people can understand the words of a second language, they do not necessarily process the words with the same emotional connection (Pavlenko, 2005). If parents feel pressured to speak in a second language, it is clear that this could have negative implications on their family well-being, and on feelings of cohesive family dynamics. It is a possibility that choosing to speak only a second, majority language to help with their development may be undermining the benefit of utilising a home language, at least for some aspects of communication.

There are a handful of studies relating specifically to autism and wellbeing, but the limited findings are comparable to neurotypical findings. Kremer-Sadlik (2005), for example, interviewed immigrant parents with autistic children, and found that parents using only English with their children led to a decline in interactions between the parent and child and a decline in the children's participation in family conversations. Similar studies have also found parents to report feeling less restricted and closer to their autistic children when communicating in their native language (Kim \& Roberti, 2014; Yu, 2013). There is some evidence to suggest that speaking a minority language with an autistic child may be particularly important for the development of family bonds. Hampton et al. (2017) report that for parents with autistic children, minority language-use was frequently associated with expressions and affection between parent and child. When parents of neurotypical children were 
asked the same question, although they valued the minority language because of its links to heritage, they did not refer to parent-child bonds as frequently.

Research indicates that children with autism can be particularly dependent on caregivers rather than others, such as school peers. For example, autistic children are more likely than their typically developing siblings to acquire their mother's accent (Baron-Cohen \& Staunton, 1994). This could suggest that the family bonds may play a particularly important role in the well-being of autistic people, given the often-reduced frequency of peer relationships (Calder, Hill, \& Pellicano, 2013; Frankel et al., 2010). As such, the socialcultural, and emotional benefits as well as linguistic benefits of exposure to the minority language in the home may be especially important for autistic children.

Enriched parent-child interactions are important for successful development, given their role in attachment (De Wolff \& van Ijzendoorn, 1997), joint attention and the achievement of linguistic milestones (Tamis-LeMonda, Bornstein, \& Baumwell, 2001). For autistic children who have social, linguistic and communicative challenges, it may be all the more important to benefit from high quality social and linguistic input, and for some families achieving such input may entail the use of the parents' native language. In additional to the transfer of quality language, speaking one language to a child with autism (but two languages with other family members) could also create obstacles in terms of family integration. In families where one parent speaks their own home language to their children, such patterns of communication provide opportunities for separate conversations rather than time for families to communicate together (Wang \& Casillas, 2013). Furthermore, when a parent is excluded from a conversation because of a barrier in understanding, parents frequently report feeling a sense of desertion and isolation. Over time, this can lead to a negative transfer of emotions into other aspects of family life (Wang \& Casillas 2013). It is likely that children who are excluded from speaking a second language with other family members may also share similar emotional experiences. Given the importance of these findings on wellbeing, it will be crucial for researchers and practitioners to incorporate this view into evidence-based guidelines for caregivers.

\section{Methodological Challenges}

Although there is an increasing body of research on how bilingualism influences development for autistic children, important questions remain about the exact consequences on cognitive development. Evaluation of the autism and bilingualism literature is confounded by a number of methodological challenges, limiting the extent 
to which this evidence is informative. We consider methodological priorities that should be considered for future research, to ensure that findings are replicable, comparable and incorporating systematic and standardised methods.

\section{Heterogeneity and bilingualism}

Varied experiences of bilingual environments will influence development in numerous ways. In the autism and bilingualism literature, bilingual exposure is defined by a number of parameters that are varied and unstandardised. These range from arbitrary cut-off points relating to daily language use (De Bruin, 2019), including grouping participants by sequential versus simultaneous bilingualism, language switching frequency or proficiency questionnaires. Whilst all are arguably valid elements of a bilingual experience, there is evidence from the adult literature that using single measures of bilingualism can lead to varied findings (De Bruin, 2019). Although heterogeneity in methods and measurements can allow for greater analytic flexibility, it is likely that research using different measures of bilingualism accounts at least some of the effects (or lack thereof) of bilingualism on cognitive functions. For example, an EF advantage may be more apparent for simultaneous than sequential bilinguals (Carlson \& Meltzoff, 2008) and EF skills may vary according to language use, such that engaging in more frequent language switches in everyday life may result in better EF performance (Soveri, Rodriguez-Fornells, \& Laine, 2011).

There are several approaches that can be undertaken to reduce the variability between findings. Researchers have recommended the use of more detailed assessments, including extensive, standardised questionnaires, that incorporate multiple aspects of a bilingual environment described above. Additionally, using continuous variables over a categorical method could capture fine-grained differences in bilingual exposure. Recent studies have suggested that monolingual language processing is more heterogeneous that previously suggested. For example, passive exposure to languages in multicultural communities could be sufficient promoting new language learning skills, (Bice \& Kroll, 2019) even with the absence of attention (Gullberg et al., 2010). Furthermore, large individual differences have been identified between the electrophysiological responses during language processing tasks in monolingual adults (Tanner \& Van Hell, 2014). This research highlights some of the difficulties in identifying homogeneous monolingual subgroups. Adopting a continuum approach would also move away bilingual versus monolingual group differences. This could range from minimal use of a second language in any setting to near-exclusive use of a minority language in the home, in order to investigate the 'dose-dependent' effects of dual language exposure, while accounting for both quantity 
and quality of exposure. Crucially, implementing a widely-used specification of what bilingualism is and how it is measured will allow for more reliable comparisons between samples; this is of particular importance in a field where sample sizes are relatively small.

\section{Measurements}

In addition to the difficulties with methods used to describe and quantify bilingualism, task impurity also contributes to problems with interpretation and generalisability. Many tasks, particularly within executive function domains are intended to measure one aspect of development; for example, inhibition or task switching. Inevitably, however, $\mathrm{EF}$ abilities rely on other cognitive processes, and it is likely that a proportion of variance on any given task is driven by processes outside of the construct that the task intended to measure (Friedman et al., 2009; Prior, 2014).

Furthermore, the development of cognitive functions is not modular in nature; rather, the product of experience-dependent processes that overlap and affect one another (Westermann et al., 2007). For example, aspects of cognitive control are related to later social communication skills (Aro et al., 2012) and early play and communication skills are linked to later language outcomes (Toth et al., 2006). In terms of bilingualism and cognition, it is possible that putative improvements in executive function skills could arguably speed up facets of social cognitive development (Kovacs, 2009; 2012). It could, therefore, be overly simplistic to assess cognitive skills and the impact of bilingualism in isolation, rather than understanding the influences of one modality on another (Hughes, 2002).

In addition to cognitive skills, other environmental factors have been overlooked. It is unclear whether effects associated with bilingualism are the result of bilingualism per se, or of associated factors. For example, bilinguals not only switch between languages but also between cultural contexts (such as different customs inside and outside the home).

The pertinent question is: how can researchers gain better insight into the mechanisms underlying their findings? First, adopting rigorous methods, such as longitudinal designs will enable researchers to measure multiple aspects of cognitive development, and in turn, to consider both causation and consequences of development (Charman, 2010). By viewing developmental changes over time, we can draw conclusions about how cognition and language development interact, moving away from static accounts. By examining longitudinal change, we can begin to answer more complex questions, such as those surrounding executive 
functions. Bilingual advantage is typically explained in developmental terms (e.g., practice switching between languages boosts children's executive functions over time, yet the majority of research has adopted a crosssectional framework. Developmentally-driven data would provide opportunities for analyses that include the strength and direction of correlations.

\section{Autism and variability}

A further factor that complicates interpretation of the literature is the heterogeneity of autism. (Bruining et al., 2010). A broad range of language and intellectual abilities are represented within autism, as well as variability in the degree to which people are affected by their autism diagnosis, including co-occurring conditions. Any potential benefits or disadvantages of bilingualism may only become apparent for certain individuals or groups. Bilingualism may be more advisable, for example, for those children who do not show a delay in language acquisition that may risk being exacerbated by bilingualism. It is also possible that bilingualism may provide beneficial training in executive function and social skills for those who possess some degree of skill in these areas, though it may tax these abilities with detrimental effect for those who demonstrate greater difficulties. There is currently a dearth of empirical literature systematically exploring the influence of heterogeneity on the consequences of bilingualism for those on the autism spectrum. Future research should establish the impact of bilingualism for different groups of individuals, including those with co-occurring intellectual disability.

\section{Discussion}

Direct research into autism and bilingualism does not currently indicate that bilingualism poses disadvantages for autistic people. Furthermore, there is preliminary evidence to suggest possible benefits in the form of improvements in non-verbal communication skills. The conclusions drawn from this literature, however, must be taken as suggestive rather than definitive, given the scarcity of the research and inconsistencies in methodologies that constrain the generalisability of these findings.

Evidence from the separate literatures addressing cognitive skills in autism and in bilingualism suggests some key areas of overlap in which bilingualism provide a theoretical basis for potentially advantageous interactions and could help reduce challenges faced by autistic people. Certain aspects of social cognition, particularly non-verbal communication, pragmatic language and theory of mind seem promising areas for future research, given substantial evidence of advantages in these areas in bilingualism and disadvantages in autism. Furthermore, qualitative work suggests a role for bilingualism in maintaining family cohesion and 
community involvement, potentially contributing to greater emotional wellbeing for autistic children and their families.

Greater circumspection is required when considering the potential positive effects of bilingualism on executive function in autistic people, given that research in this area is far less consistently supportive of a typical bilingual advantage. Problems with causality in the neurotypical bilingual literature make predictions about autism more challenging. Nevertheless, the presence of some evidence of a typical bilingual advantage leaves open the possibility that bilingualism may help to reduce difficulties in this area in autism.

Very little research has investigated the many unexplored ways in which autism and bilingualism could interact beyond the linguistic domain. Further research employing innovative designs to address open questions (such as potential advantages in gesture and multi-tasking) is required. Furthermore, it would be necessary for further research, particularly in the controversial area of executive function, to carefully determine which bilingual contexts favour any potential advantageous effects.

In addition to the potential cognitive effects of bilingualism on the individual child, research should also consider the emotional well-being of the child within the context of the family unit as a whole, and the factors that best facilitate enriched relationships between family members.

\section{Implications}

In terms of clinical practice, the tendency amongst professionals to advise families to adopt a monolingual approach with their child with autism does not seem have a solid grounding in evidence. It is vital that clinicians are aware of existing findings suggesting no detrimental effects of bilingualism in order to be able to give informed language environment recommendations to families. However, future research must overcome the methodological inconsistencies that currently makes generalisability inconceivable, in order to provide parents with a high-quality evidence base addressing how bilingualism affects learning outcomes for autistic children.

The multiple domains of overlap between areas impacted by both autism and bilingualism should promote more investigation in this field. Examining the impact of bilingualism on cognitive processes known to be negatively affected in autism, such as gesture use, theory of mind and inhibitory control, and can provide a robust test of the impact of language environment in development, as well as yielding information of practical value to the community. 
References

Adams, N. C., \& Jarrold, C. (2012). Inhibition in autism: Children with autism have difficulty in inhibiting irrelevant distractors but not prepotent responses. Journal of Autism and Developmental Disorders, 42, 1052-1063. http://dx.doi.org/10.1007/s10803-011-1345-3

American Psychiatric Association. (2013). Diagnostic and statistical manual of mental disorders (5th ed.). Washington, DC: American Psychiatric Association. http://dx.doi.org/10.1176/appi.books.9780890425596

Anderson, P. (2002). Assessment and development of executive function (EF) during childhood. Child Neuropsychology, 8, 71-82. http://dx.doi.org/10.1076/chin.8.2.71.8724

Aro, T., Eklund, K., Nurmi, J. E., \& Poikkeus, A. M. (2012). Early language and behavioral regulation skills as predictors of social outcomes. Journal of Speech, Language, and Hearing Research.

Baldimtsi, E., Peristeri, E., Tsimpli, I. M., \& Nicolopoulou, A. (2016). Bilingual Children with High Functioning Autism Spectrum Disorder: Evidence from Oral Narratives and Non-verbal Executive Function Tasks. In J. Scott \& D. Waughtal (Eds.), Proceedings of the 40th annual Boston University Conference on Language Development, (pp. 18-31). Somerville, MA: Cascadilla Press.

Baron-Cohen, S. (2000). Theory of mind and autism: A fifteen year review. In S. BaronCohen, H. Tager-Flusberg, \& D. J. Cohen (Eds.), Understanding other minds: Perspectives from developmental cognitive neuroscience (2nd ed.), (pp. 3-20). New York, NY: Oxford University Press.

Baron-Cohen, S. (2001). Theory of mind in normal development and autism. Prisme, 34, $174-183$.

Baron-Cohen, S., Leslie, A. M., \& Frith, U. (1985). Does the autistic child have a 'theory of mind'? Cognition, 21, 37-46. http://dx.doi.org/10.1016/0010-0277(85)90022-8

Baron-Cohen, S., O'Riordan, M., Stone, V., Jones, R., \& Plaisted, K. (1999). Recognition of faux pas by normally developing children and children with Asperger syndrome or high-functioning autism. Journal of Autism and Developmental Disorders, 29, 407-418. http://dx.doi.org/10.1023/A:1023035012436

Baron-Cohen, S., \& Staunton, R. (1994). Do children with autism acquire the phonology of their peers? An examination of group identification through the window of bilingualism. First Language, 14, 241-248. http://dx.doi.org/ 10.1177/014272379401404216 
Beauchamp, M. L., \& MacLeod, A. A. (2017). Bilingualism in children with autism spectrum disorder: Making evidence based recommendations. Canadian Psychology/psychologie canadienne, 58(3), 250.

Beaumont, R. B., \& Sofronoff, K. (2008). A new computerised advanced theory of mind measure for children with Asperger syndrome: The ATOMIC. Journal of Autism and Developmental Disorders, 38, 249260. http://dx.doi.org/10.1007/s10803-007-0384-2

Bialystok, E. (2009). Bilingualism: The good, the bad, and the indifferent. Bilingualism: Language and Cognition, 12, 3-11. http://dx.doi.org/10.1017/S1366728908003477.

Bialystok, E., Craik, F. I. M., Green, D. W., \& Gollan, T. H. (2009). Bilingual minds. Psychological Science in the Public Interest, 10, 89-129. http://dx.doi.org/10.1177/1529100610387084

Bialystok, E., Craik, F. I. M., Klein, R., \& Viswanathan, M. (2004). Bilingualism, aging, and cognitive control: Evidence from the Simon task. Psychology and Aging, 19, 290-303. http://dx.doi.org/10.1037/0882-7974.19.2.290

Bialystok, E., \& Martin, M. M. (2004). Attention and inhibition in bilingual children: Evidence from the dimensional change card sort task. Developmental Science, 7, 325-339. http://dx.doi.org/10.1111/j.1467-7687.2004.00351.x

Bice, K., \& Kroll, J. F. (2019). English only? Monolinguals in linguistically diverse contexts have an edge in language learning. Brain and language, 196, 104644.

Bishop, D. V. (2014). Pragmatic language impairment: A correlate of SLI, a distinct subgroup, or part of the autistic continuum?. In Speech and language impairments in children (pp. 113-128). Psychology Press.

Bishop, D. V., \& Norbury, C. F. (2002). Exploring the borderlands of autistic disorder and specific language impairment: a study using standardised diagnostic instruments. Journal of Child Psychology and Psychiatry, 43(7), 917-929.

Bloom, P., \& German, T. P. (2000). Two reasons to abandon the false belief task as a test of theory of mind. Cognition, 77, B25-B31. http://dx.doi.org/10.1016/S0010-0277(00)00096-2

Bruining, H., de Sonneville, L., Swaab, H., de Jonge, M., Kas, M., van Engeland, H., et al. 
(2010). Dissecting the Clinical Heterogeneity of Autism Spectrum Disorders through Defined Genotypes. PLoS ONE, 5: e10887. http://dx.doi.org/10.1371/journal.pone.0010887

Burack, J. A ., Iarocci, G., Bowler, D., Mottron, L. (2002). Benefits and pitfalls in the merging of disciplines: The example of developmental psychopathology and the study of persons with autism. Developmental Psychopathology, 14, 225-237.

Calder, L., Hill, V., \& Pellicano, E. (2013). Sometimes I want to play by myself:

Understanding what friendship means to children with autism in mainstream primary schools. Autism, 17, 296-316. http://dx.doi.org/10.1177/1362361312467866

Carlson, S. M., \& Meltzoff, A. N. (2008). Bilingual experience and executive functioning in young children. Developmental Science, 11, 282-298. http://dx.doi.org/10.1111/j.1467-7687.2008.00675.x

Charman, T. (2010). Developmental approaches to understanding and treating autism. Folia Phoniatrica et Logopaedica, 62(4), 166-177.

Charman, T., Pickles, A., Simonoff, E., Chandler, S., Loucas, T., \& Baird, G. (2011). IQ in children with autism spectrum disorders: data from the Special Needs and Autism Project (SNAP). Psychological medicine, 41(3), 619-627.

Chevallier, C., Kohls, G., Troiani, V., Brodkin, E. S., and Schultz, R. T. (2012). The Social Motivation Theory of Autism. Trends in Cognitive Sciences, 16, 231-239. http://doi.org/10.1016/j.tics.2012.02.007

Christ, S. E., Holt, D. D., White, D. A., \& Green, L. (2007). Inhibitory control in children with autism spectrum disorder. Journal of Autism and Developmental Disorders, 37, 1155-1165. http://dx.doi.org/10.1007/s10803-006-0259-y

Colzato, L. S., Bajo, M. T., van den Wildenberg, W., Paolieri, D., Nieuwenhuis, S., La Heij, W., \& Hommel, B. (2008). How does bilingualism improve executive control? A comparison of active and reactive inhibition mechanisms. Journal of Experimental Psychology: Learning Memory and Cognition, 34, 302-312. http://dx.doi.org/10.1037/0278-7393.34.2.302

Comeau, L., Genesee, F., \& Lapaquette, L. (2003). The modeling hypothesis and child Bilingual codemixing. International Journal of Bilingualism, 7, 113-126.

Comeau, L., Genesee, F., \& Mendelson, M. (2007). Bilingual children's repairs of breakdowns in communication. Journal of Child Language, 34, 159-174. http://dx.doi.org/10.1017/S0305000906007690 
Costa, A., Hernández, M., Costa-Faidella, J., \& Sebastián-Gallés, N. (2009). On the bilingual advantage in conflict processing: Now you see it, now you don't. Cognition, 113, 135-149. http://dx.doi.org/10.1016/j.cognition.2009.08.001

Costa A., Hernández M., \& Sebastián-Gallés, N. (2008). Bilingualism aids conflict resolution: Evidence from the ANT task. Cognition, 106, 59-86. http://dx.doi.org/10.1016/j.cognition.2006.12.013

Craik, F. I. M., \& Bialystok, E. (2006). Planning and task management in older adults: Cooking breakfast. Memory \& Cognition, 34, 1236-1249. http://dx.doi.org/10.3758/BF03193268

Dawson, G., Bernier, R., Ring, R. H. (2012). Social attention: a possible early indicator of efficacy in autism clinical trials. Journal of Neurodevelopmental Disorders, 4, 11. http://dx.doi.org/10.1186/1866-1955-4-11

De Bruin, A. (2019). Not all bilinguals are the same: A call for more detailed assessments and descriptions of bilingual experiences. Behavioral Sciences, 9(3), 33.

De Wolff, M. S., \& van Ijzendoorn, M. H. (1997). Sensitivity and attachment: A Metaanalysis on parental antecedents of infant attachment. Child Development, 68, 571-591. http://dx.doi.org/10.1111/j.1467-8624.1997.tb04218.x

Dover, C. J., \& Le Couteur, A. (2007). How to diagnose autism. Archives of disease in childhood, 92(6), 540545.

Drysdale, H., van der Meer, L., \& Kagohara, D. (2015). Children with Autism Spectrum Disorder from Bilingual Families: a Systematic Review. Review Journal of Autism and Developmental Disorders, 2, 26-38. http://dx.doi.org/10.1007/s40489-014-0032-7

Duñabeitia, J. A., Hernández, J. A., Antón, E., Macizo, P., Estévez, A., Fuentes, L. J., \& Carreiras, M. (2014). The inhibitory advantage in bilingual children revisited. Experimental Psychology, 61, 234-251. http://dx.doi.org/10.1027/1618-3169/a000243

Durrleman, S., Hippolyte, L., Zufferey, S., Iglesias, K., Hadjikhani, N. (2015). Complex syntax in autism spectrum disorders: a study of relative clauses. International Journal of Language and Communication Disorders, 50, 260-267. http://dx.doi.org/10.1111/1460-6984.12130. 
Emerson, M. J., \& Miyake, A. (2003). The role of inner speech in task switching: A dual-task investigation. Journal of Memory and Language, 48(1), 148-168.

Feltmate, K., \& Kay-Raining Bird, E. (2008). Language learning in four bilingual children with Down syndrome: A detailed analysis of vocabulary and morphosyntax. Canadian Journal of Speech-Language Pathology and Audiology, 32, 6-20. Retrieved from http://cjslpa.ca/

Frankel, F., Myatt, R., Sugar, C., Whitham, C., Gorospe, C. M., \& Laugeson, E. (2010). A randomized controlled study of parent-assisted children's friendship training with children having autism spectrum disorders. Journal of Autism and Developmental Disorders, 40, 827-842. http://dx.doi.org/10.1007/s10803-009-0932-z

Friedman, N. P., Miyake, A., Corley, R. P., Young, S. E., DeFries, J. C., \& Hewitt, J. K. (2006). Not all executive functions are related to intelligence. Psychological science, 17(2), 172-179.

Gathercole, V. C. M., Thomas, E. M. (2009). Bilingual first language development: Dominant language takeover, threatened minority language take-up. Bilingualism: Language and Cognition 12, 213-237. http://dx.doi.org/10.1017/S1366728909004015

Gathercole, V. C. M., Thomas, E. M., Viñas Guasch, N., Kennedy, I., Prys, C., Young, N., Roberts, E. J., Hughes, E. K., \& Jones, L. (2016). Teasing apart factors influencing Executive Function performance in bilinguals and monolinguals at different ages. Linguistic Approaches to Bilingualism, 6, 605-647.

Geller, E. (1998). An investigation of communication breakdowns and repairs in verbal autistic children. British Journal of Developmental Disabilities, 44(87), 71-85. http://dx.doi.org/10.1179/096979598799156092

Geurts, H. M., Corbett, B., \& Solomon, M. (2009). The paradox of cognitive flexibility in autism. Trends in Cognitive Science, 13, 74-82. http://dx.doi.org/10.1016/j.tics.2008.11.006.

Goetz, P. J. (2003). The effects of bilingualism on theory of mind development. Bilingualism: Language and Cognition, 6, 1-15. http://dx.doi.org/10.1017/S1366728903001007.

Goldberg, M. C., Mostofsky, S. H., Cutting, L. E., Mahone, E. M., Astor, B. C., Denckla, M. 
B., \& Landa, R. J. (2005). Subtle executive impairment in children with autism and children with ADHD. Journal of Autism and Developmental Disorders, 35, 279-293.

http://dx.doi.org/10.1007/s10803-005-3291-4

Goldin-Meadow, S., \& Singer, M. A. (2003). From children's hands to adults' ears: Gesture's role in the learning process. Developmental psychology, 39(3), 509.

Gonzalez-Barrero, A. M., \& Nadig, A. (2016). Verbal fluency in bilingual children with Autism Spectrum Disorders. Linguistic Approaches to Bilingualism (published online). http://dx.doi.org/10.1075/lab.15023.gon

Gonzalez-Barrero, A. M., \& Nadig, A. S. (2019). Can Bilingualism Mitigate Set-Shifting Difficulties in Children With Autism Spectrum Disorders?. Child development, 90(4), 1043-1060.

Grice, H. P. (1975). Logic and conversation. In P. Cole and J. Morgan (Eds.), Syntax and Semantics III: Speech Acts (pp. 183-198). New York, NY: Academic Press.

Grosjean, F. (2010). Bilingual: Life and reality. Cambridge, MA: Harvard University Press. http://dx.doi.org/10.4159/9780674056459

Gullberg, M. (2010). Methodological reflections on gesture analysis in second language acquisition and bilingualism research. Second language research, 26(1), 75-102.

Gullberg, M., Roberts, L., Dimroth, C., Veroude, K., \& Indefrey, P. (2010). Adult language learning after minimal exposure to an unknown natural language. Language Learning, 60, 5-24.

Hall, S., Rumney, L., Holler, J., \& Kidd, E. (2013). Associations among play, gesture and early spoken language acquisition. First Language, 33, 294-312. http://dx.doi.org/10.1177/0142723713487618.

Halle, T. G., Whittaker, J. V., Zepeda, M., Rothenberg, L., Anderson, R., Daneri, P., ...Buysse, V. (2014). The social-emotional development of dual language learners: Looking back at existing research and moving forward with purpose. Early Childhood Research Quarterly, 29, 734-749. http://dx.doi.org/10.1016/j.ecresq.2013.12.002

Hambly, C., \& Fombonne, E. (2012). The impact of bilingual environments on language development in children with autism spectrum disorders. Journal of Autism and Developmental Disorders, 42, 13421352. http://dx.doi.org/10.1007/s10803-011-1365-z 
Hampton, S., Rabagliati, H., Sorace, A., \& Fletcher-Watson, S. (2017). Autism and bilingualism: A qualitative interview study of parents' perspectives and experiences. Journal of Speech, Language, and Hearing Research, 60(2), 435-446.

Han, W.-J., \& Huang, C.-C. (2010). The forgotten treasure: Bilingualism and Asian children's emotional and behavioral health. American Journal of Public Health, 100, 831-838. http://dx.doi.org/10.2105/AJPH.2009.174219

Happé, F. (1993). Communicative competence and theory of mind in autism: A test of relevance theory. Cognition, 48, 101-119. http://dx.doi.org/10.1016/0010-0277(93)90026-R

Hill, E. L. (2004). Executive dysfunction in autism. Trends in Cognitive Science, 8, $26-32$. http://dx.doi.org/10.1016/j.tics.2003.11.003

Hill, E. L., \& Bird, C. M. (2006). Executive processes in Asperger syndrome: Patterns of performance in a multiple case series. Neuropsychologia, 44, 2822-2835. http://dx.doi.org/10.1016/j.neuropsychologia.2006.06.007

Hoff, E., Core, C., Place, S., Rumiche, R., Señor, M., \& Parra, M. (2012). Dual language exposure and early bilingual development. Journal of child language, 39(1), 1-27.

Holowka, S., Brosseau-Lapré, F., \& Petitto, L. A. (2002). Semantic and conceptual knowledge underlying young bilingual babies' first signs and words. Language Learning, 55, 205-262. http://dx.doi.org/10.1111/0023-8333.00184

Hughes, C. (2002). Executive functions and development: Emerging themes. Infant and Child Development: An International Journal of Research and Practice, 11(2), 201-209.

Humphrey, A. D., \& Valian, V. V. (2012). Multilingualism and cognitive control: Simon and flanker task performance in monolingual and multilingual young adults. Paper presented at $53 \mathrm{rd}$ Annual meeting of the psychonomic society, Minneapolis, MN. Abstract retrieved from http://www.gc.cuny.edu/Public-Programming/Calendar/Detail?id=13637

Iverson, J. M., \& Goldin-Meadow, S. (2005). Gesture paves the way for language development. Psychological science, 16(5), 367-371.

Kay-Raining Bird, E., Lamond, E., \& Holden, J. (2012). Survey of bilingualism in autism spectrum disorders. International Journal of Language \& Communication Disorders, 47, 52-64. http://dx.doi.org/10.1111/j.1460-6984.2011.00071.x 
Kim, H. U., \& Roberti, M. (2014). “Tengo que habla español. Yo no entiendo ingles!”: A qualitative case study on a bilingual child with autism spectrum conditions. The Journal of Special Education Apprenticeship, 3, 1-15. Retrieved from http://www.josea.info/

Kjelgaard, M. M., \& Tager-Flusberg, H. (2001). An investigation of language impairment in autism: Implications for genetic subgroups. Language and Cognitive Processes, 16, 287-308. http://dx.doi.org/10.1080/01690960042000058

Kleinhans, N., Akshoomoff, N., \& Delis, D. C. (2005). Executive functions in autism and Asperger's disorder: flexibility, fluency, and inhibition. Developmental neuropsychology, 27(3), 379-401.

Korkman, M., Stenroos, M., Mickos, A., Westman, M., Ekholm, P., \& Byring, R. (2012), Does simultaneous bilingualism aggravate children's specific language problems? Acta Paediatrica, 101, 946-952. http://dx.doi.org/10.1111/j.1651-2227.2012.02733.x

Kovács, Á. M. (2009). Early bilingualism enhances mechanisms of false-belief reasoning. Developmental Science, 12, 48-54. http://dx.doi.org/10.1111/j.14677687.2008.00742.x

Kremer-Sadlik, T. (2005). To be or not to be bilingual: Autistic children from multilingual families. In J. Cohen, K. T. McAlister, K. Rolstad, \& J. MacSwan (Eds.), Proceedings of the 4th International Symposium on Bilingualism (pp.1225-1234). Somerville, MA: Cascadilla Press.

Kroll, J. F., \& Bialystok, E. (2013). Understanding the consequences of bilingualism for language processing and cognition. Journal of cognitive psychology, 25(5), 497-514.

Kroll, J. F., Bobb, S. C., Misra, M., \& Guo, T. (2008). Language selection in bilingual speech: Evidence for inhibitory processes. Acta Psychologica, 128, 416-430. http://dx.doi.org/10.1016/j.actpsy.2008.02.001

Leekam, S. R., Prior, M. R., \& Uljarevic, M. (2011). Restricted and repetitive behaviors in autism spectrum disorders: a review of research in the last decade. Psychological bulletin, 137(4), 562.

Lopez, B. R., Lincoln, A. J., Ozonoff, S., \& Lai, Z. (2005). Examining the relationship between executive functions and restricted, repetitive symptoms of Autistic disorder. Journal of Autism and Developmental Disorders, 35, 445-460. http://dx.doi.org/10.1007/s10803-005-5035-x

Manwaring, S. S., Mead, D. L., Swineford, L., \& Thurm, A. (2017). Modelling gesture use and early language development in autism spectrum disorder. International journal of language \& communication disorders, 52(5), 637-651.

Marian, V. (2018). Bilingual research methods. In An Introduction to Bilingualism (pp. 12-36). Routledge. 
Marinova-Todd, S. H., \& Mirenda, P. (2015). Autism spectrum disorders in bilingual children. In J. Patterson, \& B. Rodriguez (Eds.), Multilingual Perspectives on Child Language Disorders. Multilingual Matters.

Martin-Rhee, M., \& Bialystok, E. (2008). The development of two types of inhibitory control in monolingual and bilingual children. Bilingualism: Language and Cognition, 11, 81-93. http://dx.doi.org/10.1017/S1366728907003227.

Meir, N., \& Novogrodsky, R. (2019). Syntactic abilities and verbal memory in monolingual and bilingual children with High Functioning Autism (HFA). First Language, 0142723719849981.

Mitchell, S., Brian, J., Zwaigenbaum, L., Roberts, W., Szatmari, P., Smith, I., \& Bryson, S. (2006). Early language and communication development of infants later diagnosed with autism spectrum disorder. Journal of Developmental \& Behavioral Pediatrics, 27, S69-S78. http://dx.doi.org/10.1097/00004703-200604002-00004

Morton, J. B, \& Harper, S. N. (2007). What did Simon say? Revisiting the bilingual advantage. Developmental Science, 10, 719-726. http://dx.doi.org/10.1111/j.1467-7687.2007.00623.x

Nicoladis, E., Pika, S., \& Marentette, P. (2009). Do French-English bilingual children gesture more than monolingual children? Journal of Psycholinguistic Research, 38, 573-585. http://dx.doi.org/10.1007/s10936-009-9121-7

Norbury, C. F., \& Bishop, D. V. (2002). Inferential processing and story recall in children with communication problems: a comparison of specific language impairment, pragmatic language impairment and highfunctioning autism. International Journal of Language \& Communication Disorders, 37(3), 227-251.

Ohashi, J. K., Mirenda, P., Marinova-Todd, S. H., Hambly, C., Fombonne, E., Szatmari, P. ... The Pathways in ASD Study Team (2012). Comparing early language development in monolingual- and bilingual- exposed young children with autism spectrum disorders. Research in Autism Spectrum Disorders, 6, 890-897.http://dx.doi.org/10.1016/j.rasd.2011.12.002.

Opitz, B., \& Degner, J. (2012). Emotionality in a second language: It's a matter of time. Neuropsychologia 50, 1961-1967. http://dx.doi.org/10.1016/j.neuropsychologia.2012.04.021

Ozonoff, S., \& McEvoy, R. E. (1994). A longitudinal study of executive function and theory of mind development in autism. Development and Psychopathology, 6, 415-432

Ozonoff, S., \& Strayer, D. L. (1997). Inhibitory function in nonretarded children with autism. Journal of Autism Developmental Disorders, 27, 59 -77. http://dx.doi.org/10.1023/A:1025821222046 
Paap, K. R., \& Greenberg, Z. I. (2013). There is no coherent evidence for a bilingual advantage in executive processing. Cognitive Psychology, 66, 232-258. http://dx.doi.org/10.1016/j.cogpsych.2012.12.002

Panayiotou, A. (2004). Switching codes, switching code: Bilinguals' emotional responses in English and Greek. Journal of multilingual and multicultural development, 25(2-3), 124-139.

Paradis, J., Nicoladis, E., Crago, M., \& Genesee, F. (2011). Bilingual children's acquisition of the past tense: A usage-based approach. Journal of child language, 38(3), 554-578.

Parsons, L., Cordier, R., Munro, N., Joosten, A., \& Speyer, R. (2017). A systematic review of pragmatic language interventions for children with autism spectrum disorder. PloS one, 12(4).

Paul, R. (2007). Communication and its development in autism spectrum disorders. In F. Volkmar (Ed.), Autism and pervasive developmental disorders (2nd ed.) (pp. 129-155). Cambridge: Cambridge University Press.

Pavlenko, A. (2005). Bilingualism and Thought. Oxford University Press.

Paul, R., Landa, R., \& Simmons, E. (2014). Assessing and treating communication. In McPartland, J., Klin, A., \& Volkmar, F. (Eds.), Asperger syndrome: Assessing and treating highfunctioning autism spectrum disorder (2nd ed.), (pp. 103-142). New York, NY: Guilford Press.

Petersen, J. M., Marinova-Todd, S. H., \& Mirenda, P. (2012). Brief report: An exploratory study of lexical skills in bilingual children with autism spectrum disorder. Journal of Autism and Developmental Disorders, 42, 1499-1503. http://dx.doi.org/10.1007/s10803-011-1366-y

Petitto, L. A., Katerelos, M., Levy, B. G., Gauna, K., Tétreault, K., \& Ferraro, V. (2001). Bilingual signed and spoken language acquisition from birth: Implications for the mechanisms underlying early bilingual language acquisition. Journal of Child Language, 28, 453-496. http://dx.doi.org/10.1017/S0305000901004718

Pierce, K., Conant, D., Hazin, R., Stoner, R., Desmond, J. (2011). Preference for geometric patterns early in life as a risk factor for autism. Archives of General Psychiatry, 68, 101-109. http://dx.doi.org/10.1001/archgenpsychiatry.2010.113.

Prior, A. \& Gollan, T. H. (2011). Good language-switchers are good task-switchers: Evidence from Spanish-English and Mandarin-English bilinguals. Journal of International Neuropsychological Society, 17, 682-691. http://dx.doi.org/10.1017/S1355617711000580

Prior, A., \& MacWhinney, B. (2010). A bilingual advantage in task switching. Bilingualism: 
Language and Cognition, 13, 253-262. http://dx.doi.org/10.1017/S1366728909990526

Prutting, C. A., \& Kittchner, D. M. (1987). A clinical appraisal of the pragmatic aspects of language. Journal of Speech and hearing Disorders, 52(2), 105-119.

Reetzke, R., Zou, X., Sheng, L., \& Katsos, N. (2015). Communicative development in bilingually exposed Chinese children with autism spectrum disorders. Journal of Speech, Language, and Hearing Research, 58, 813-825. http://dx.doi.org/10.1044/2015_JSLHR-L-13-0258

Rontu, H. (2007). Codeswitching in triadic conversational situations in early bilingualism. International Journal of Bilingualism, 11, 337-358. http://dx.doi.org/10.1177/13670069070110040101

Rubio-Fernández, P., \& Glucksberg, S. (2012). Reasoning about other people's beliefs: Bilinguals have an advantage. Journal of Experimental Psychology: Learning, Memory, and Cognition. 38, 211-217. http://dx.doi.org/10.1037/a0025162

Russell, J., Jarrold, C., \& Hood, B. (1999). Two intact executive capacities in children with autism: Implications for the core executive dysfunctions in the disorder. Journal of Autism and Developmental Disorders, 29, 103-112.

Scheeren, A. M., de Rosnay, M., Koot, H. M., \& Begeer, S. (2013). Rethinking theory of mind in highfunctioning autism spectrum disorder. Journal of Child Psychology and Psychiatry, 54, 628-635. http://dx.doi.org/10.1111/jcpp.12007

Senju, A. (2012). Spontaneous theory of mind and its absence in autism spectrum disorders. Neuroscientist, 18, 108-113. http://dx.doi.org/10.1177/1073858410397208

Sidera, F., Perpiñà, G., Serrano, J., \& Rostan, C. (2018). Why is theory of mind important for referential communication?. Current Psychology, 37(1), 82-97.

Siegal, M., Iozzi, L., \& Surian, L. (2009). Bilingualism and conversational understanding in young children. Cognition, 110, 115-122. http://dx.doi.org/10.1016/j.cognition.2008.11.002

Siegal, M., Surian, L., Matsuo, A., Geraci, A., Iozzi, L., Okumura, Y., \& Itakura, S. (2010). Bilingualism accentuates children's conversational understanding. PLoS ONE, 5, e9004. http://dx.doi.org/10.1371/journal.pone.0009004

Soveri, A., Rodriguez-Fornells, A., \& Laine, M. (2011). Is there a relationship between language switching and executive functions in bilingualism? Introducing a within group analysis approach. Frontiers in Psychology, 2, 183. http://dx.doi.org/10.3389/fpsyg.2011.00183

Surian, L., Baron-Cohen, S., \& van der Lely, H. (1996). Are children with autism deaf to 
Gricean Maxims? Cognitive Neuropsychiatry, 1, 55-72.

http://dx.doi.org/10.1080/135468096396703

Tager-Flusberg, H. (2004). Do Autism and Specific Language Impairment Represent

Overlapping Language Disorders? In M. L. Rice, \& S. F. Warren (Eds.), Developmental Language Disorders. From Phenotypes to Etiologies (pp. 31-52). Lawrence Erlbaum Associates, Publishers: London

Tager-Flusberg, H., Rogers, S., Cooper, J., Landa, R., Lord, C., Paul, R., ... \& Yoder, P. (2009). Defining spoken language benchmarks and selecting measures of expressive language development for young children with autism. Journal of Speech, Language, \& Hearing Research, 52, $643-652$.

Tamis-LeMonda, C. S., Bornstein, M. H., \& Baumwell, L. (2001). Maternal responsiveness and children's achievement of language milestones. Child Development, 72, 748-767. http://dx.doi.org/10.1111/1467-8624.00313

Tanner, D., \& Van Hell, J. G. (2014). ERPs reveal individual differences in morphosyntactic processing. Neuropsychologia, 56, 289-301.

Toth, K., Munson, J., Meltzoff, A. N., \& Dawson, G. (2006). Early predictors of communication development in young children with autism spectrum disorder: Joint attention, imitation, and toy play. Journal of autism and developmental disorders, 36(8), 993-1005.

Tseng, V. \& Fuligni, A. J. (2000). Parent-adolescent language use and relationships among immigrant families with East Asian, Filipino, and Latin American backgrounds. Journal of Marriage and Family, 62, 465476. http://dx.doi.org/10.1111/j.1741-3737.2000.00465.x

Uljarević, M., Katsos, N., Hudry, K., \& Gibson, J. L. (2016). Practitioner Review: Multilingualism and neurodevelopmental disorders-an overview of recent research and discussion of clinical implications. Journal of Child Psychology and Psychiatry, 57(11), 1205-1217.

Valian, V. (2015). Bilingualism and cognition. Bilingualism: Language and Cognition, 18(1), 3-24.

Valicenti-McDermott, M., Tarshis, N., Schouls, M., Galdston, M., Hottinger, K., Seijo, R., ...Shinnar, S. (2013). Language differences between monolingual English and bilingual EnglishSpanish young children with autism spectrum disorders. Journal of Child Neurology, 28, 945-948. http://dx.doi.org/10.1177/0883073812453204.

Van Eylen, L., Boets, B., Steyaert, J., Evers, K., Wagemans, J. \& Noens, I. (2011). 
Cognitive flexibility in autism spectrum disorder: Explaining the inconsistencies? Research in Autism Spectrum Disorders, 5, 1390-1401 http://dx.doi.org/10.1016/j.rasd.2011.01.025

Verkuyten, M., \& Zaremba, K. (2005). Interethnic relations in a changing political context. Social Psychology Quarterly, 68(4), 375-386.

Wang, H. T., \& Casillas, N. (2013). Asian American parents' experiences of raising children with autism: Multicultural family perspective. Journal of Asian and African Studies, 48(5), 594-606.

Watson, L. R., Crais, E. R., Baranek, G. T., Dykstra, J. R., \& Wilson, K. P. (2013).

Communicative gesture use in infants with and without autism: A retrospective home video study. American Journal of Speech-Language Pathology, 22, 25-39. http://dx.doi.org/10.1044/10580360(2012/11-0145)

White, S. J., Burgess, P. W., Hill, E. L. (2009). Impairments in “open-ended” executive function tests in autism. Autism Research, 2, 138-147. http://dx.doi.org/10.1002/aur.78

Westermann, G., Mareschal, D., Johnson, M. H., Sirois, S., Spratling, M. W., \& Thomas, M. S. (2007). Neuroconstructivism. Developmental science, 10(1), 75-83.

Whitehouse, A. J., Watt, H. J., Line, E. A., \& Bishop, D. V. (2009). Adult psychosocial outcomes of children with specific language impairment, pragmatic language impairment and autism. International Journal of Language \& Communication Disorders, 44(4), 511-528.

Yow, W. Q., \& Markman, E. M. (2011). Young bilingual children's heightened sensitivity to referential cues. Journal of Cognition and Development, 12, 12-31. http://dx.doi.org/10.1080/15248372.2011.539524

Yu, B. (2013). Issues in bilingualism and heritage language maintenance: Perspectives of minority-language mothers of children with autism spectrum disorders. American Journal of Speech Language Pathology, 22, 10-24. http://dx.doi.org/10.1044/1058-0360(2012/10-0078)

Yu, B. (2016). Code-switching as a communicative resource within routine, bilingual family interactions for a child on the autism spectrum. Perspectives of the ASHA Special Interest Groups, 1, 17-28. http://dx.doi.org/10.1044/persp1.SIG14.17 